\title{
Determination of Vanadium in Alloyed Steels by Glow Discharge Emission Spectrometry with a Dual-Cathode Lamp
}

\author{
Kazuaki Wagatsuma and Kichinosuke Hirokawa \\ The Institute for Materials Research, Tohoku University, Katahira, Sendai 980, Japan
}

\begin{abstract}
A dual-cathode glow discharge lamp was successfully applied to the determination of vanadium in commercial tool steels. A unique feature of our lamp is its capability to eliminate undesired argon emission signals. In the case of the vanadium determination, an analytical line, V I $437.92 \mathrm{~nm}$ overlaps with the Ar II $437.97 \mathrm{~nm}$ line. However, an interference-free detection of this line can be performed using the lamp, leading to accurate analyses of $0.1-2.5 \%$ vanadium in steel samples.
\end{abstract}

Keywords Emission spectrometry, dual-cathode, glow discharge lamp, direct analysis of solid sample, vanadium determination

Direct sampling from a solid specimen, which, in most cases, is performed through cathode sputtering, is a major advantage in glow discharge emission spectrometry. Troublesome decomposition and dissolution procedures of solids can be omitted, resulting in a minimization of contamination from such things as acids and solvents.

Grimm-type glow discharge lamps have proven to be useful for elemental analyses of surfaces. ${ }^{1-5}$ In addition to direct solid sampling, it is worth pointing out the following features. The emission lines observed with the lamp have narrow spectral line widths due to discharge under reduced pressure; their intensities are almost free from self-absorption, thus leading to a wide linearity of working curves. ${ }^{6}$ Furthermore, since the discharge is very stable, it is expected that the emission intensities can be estimated more accurately.

In general, argon is employed as a plasma gas in the Grimm-type glow discharge analyses, since the sputter rates are effectively high. Many emission lines of argon (Ar I and Ar II) are also detected from the glow discharge plasmas. ${ }^{7}$ In some cases, these gas lines may overlap with the analytical lines of sample species. Such interference becomes a serious problem, especially in quantitative analyses of minor elements in samples. It is therefore effective to attempt to separate the signals of the analytical lines from those of the gas emission lines.

For this purpose, we have suggested a dual-cathode glow discharge lamp comprising three electrodes. ${ }^{8}$ Its performance has already revealed that the selective detection of lines derived from samples has been successfully carried out. ${ }^{8,9}$ Further, in a previous study 9 we reported on the determinations of both manganese and chromium in low-alloyed steels by the use of this lamp.

In this study, the dual-cathode glow discharge lamp was applied to the determination of vanadium in tool steels; this is industrially important since vanadium is a popular alloyed element used as an additive to improve the mechanical properties of steel materials. Some of the analytical lines of vanadium were found to suffer spectral interference from the argon lines. The spectral interference was successfully overcome.

\section{Experimental}

The structure of the dual-cathode glow lamp employed has been detailed elsewhere. ${ }^{8}$ The operating principle of this lamp is described briefly. Figure 1 illustrates the configuration of the electrodes as well as

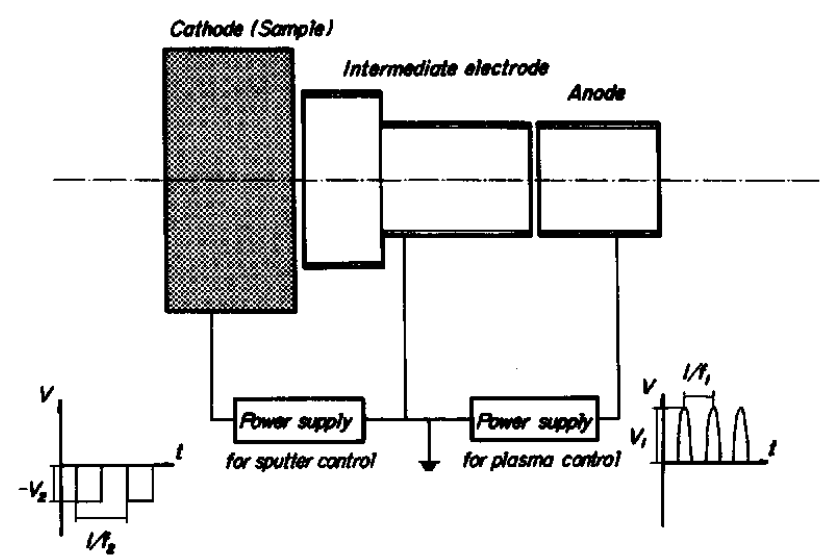

Fig. 1 Simplified diagram of the electrodes employed in the dual-cathode glow discharge lamp. 
its operating conditions under a pulsed-discharge voltage mode. The lamp comprises three electrodes: an anode, an intermediate electrode and a cathode. Hollow cathode plasmas were generated in the intermediate electrode, and were sustained by a pulsed voltage $\left(V_{1}\right)$ supplied between the anode and the intermediate electrode. The wave pattern of the discharge voltage was a rectified half-sine form at a frequency of $f_{1}$. A negative bias voltage $\left(V_{2}\right)$ was supplied between the intermediate electrode and the cathode (sample) with a different power source. The wave pattern of the bias voltage was a square wave form at a frequency of $f_{2}$.

The spectral lines from the lamp would be expected to be doubly modulated at frequencies of $f_{1}$ and $f_{2}$. The only emission lines of the sputtered atoms (samples) can be modulated at $f_{2}{ }^{8}$ A lock-in amplifier, which is tuned to a frequency of $f_{2}$, is used to select the desired components from the overall signals. In this study, in order to achieve good noise characteristics, $f_{1}$ and $f_{2}$ were predetermined at 807 and $108 \mathrm{~Hz}$, respectively. Hollow cathode discharges were produced at a voltage $\left(V_{1}\right)$ of $c a .380 \mathrm{~V}$ and at an average current of $110 \pm 10$ $\mathrm{mA}$, which were restricted by the performance of the power supply device used. The negative bias voltage $\left(V_{2}\right)$ was selected to be $-150 \mathrm{~V}$.

Standard samples of iron-vanadium binary alloys were prepared in order to estimate the calibration curves for each analytical line. These samples were available from The Iron and Steel Institute of Japan (FXS-series) as the standards for X-ray fluorescence analysis. ${ }^{10}$ Table 1 lists the content of vanadium in the standard samples as well as the calculated atomic ratios of $\mathrm{V} / \mathrm{Fe}$. In addition to vanadium, the other elements, for example, $\mathrm{Cr}, \mathrm{Mo}$ and $\mathrm{W}$, are usually alloyed in commercial tool steels. It is therefore important to investigate the effect of these third elements on the analytical results. Using the resultant calibration factors, a determination of vanadium in Fe-V-X ternary standard samples (FXS-series) was made in order to estimate the influence of the other alloyed elements. Furthermore, the dual-cathode lamp was applied to a practical analysis of commercial tool steels; the analytical results were compared with certified values established by chemical analyses. ${ }^{11}$

Pure argon gas was used as a plasma gas. The optimum gas pressure was $2.7 \times 10^{2} \mathrm{~Pa}$ for the maximum emission intensities.

Table 1 Standard samples of Fe-V binary alloy for calibration

\begin{tabular}{cccc}
\hline Sample & V wt $\%$ & V at $\%$ & V/Fe \\
\hline FXS-382 & 0.21 & 0.24 & $2.4 \times 10^{-3}$ \\
FXS-383 & 0.48 & 0.56 & $5.7 \times 10^{-3}$ \\
FXS-384 & 1.00 & 1.15 & $1.17 \times 10^{-2}$ \\
FXS-385 & 2.04 & 2.34 & $2.41 \times 10^{-2}$ \\
\hline
\end{tabular}

\section{Results and Discussion}

\section{Analytical lines of vanadium}

The spectra of vanadium emitted from glow discharges comprise many emission lines. Though no predominantly intense lines appear in the spectra, the atomic emission lines in the wavelength range between 438 and $441 \mathrm{~nm}$ were found to be relatively sensitive. As indicated in Table 2, these lines were identified to the transitions of which excitation energies are $c a .3 .1 \mathrm{eV} .{ }^{12}$ One can employ these vanadium lines as analytical lines in steel analyses. However, some Ar II emission lines also appear at these wavelengths, which may cause spectral interference in the detection of the vanadium lines. Table 3 summarizes the spectral interference of argon lines with the analytical lines of vanadium. It should be noted that the VI $437.92 \mathrm{~nm}$ line, which is the most intense of all the analytical lines listed in Table 2, overlaps with the line Ar II $437.97 \mathrm{~nm}$. Especially, this effect must be more seriously taken into consideration when a spectrometer having a lower resolution power is used. Furthermore, it can be deduced from Table 3 that the Fe I $438.59 \mathrm{~nm}$ line may be affected by the ArII $437.61 \mathrm{~nm}$ line when the emission intensity is estimated.

Two different modulation modes were used for a comparison between the conventional and interference-

Table 2 Analytical lines of vanadium employed

\begin{tabular}{cccc}
\hline $\begin{array}{c}\text { Wavelength/ } \\
\mathrm{nm}\end{array}$ & \multicolumn{2}{c}{ Assignment (eV) } & Relative \\
Upper & Lower & intensity \\
\hline I 437.92 & ${ }^{6} \mathrm{~F}_{11 / 2}(3.13)$ & ${ }^{6} \mathrm{D}_{9 / 2}(0.30)$ & 3.8 \\
I 439.00 & ${ }^{6} \mathrm{~F}_{7 / 2}(3.10)$ & ${ }^{6} \mathrm{D}_{s / 2}(0.28)$ & 1.7 \\
I 439.52 & ${ }^{6} \mathrm{~F}_{5 / 2}(3.09)$ & ${ }^{6} \mathrm{D}_{3 / 2}(0.27)$ & 1.0 \\
I 440.85 & ${ }^{6} \mathrm{~F}_{3 / 2}(3.08)$ & ${ }^{6} \mathrm{D}_{3 / 2}(0.27)$ & 2.9 \\
& ${ }^{6} \mathrm{~F}_{1 / 2}(3.07)$ & ${ }^{6} \mathrm{D}_{1 / 2}(0.26)$ & \\
\hline
\end{tabular}

a. The relative intensities are estimated from normalization with respect to the intensity of V I $439.52 \mathrm{~nm}$.

Table 3 Spectral interferences of argon lines with analytical lines of vanadium in the wavelengths $437-442 \mathrm{~nm}$

\begin{tabular}{ccc}
\hline Vanadium & Iron & Argon \\
\hline I 437.92 & I 437.59 & II 437.61 \\
& I 438.36 & II 437.97 \\
I 439.00 & & \\
I 439.52 & & II 440.02 \\
I 440.06 & & II 440.09 \\
& I 440.48 & \\
I 440.85 & I $441.51^{\mathrm{a}}$ & \\
\hline
\end{tabular}

a. Internal standard line of iron in this study. 


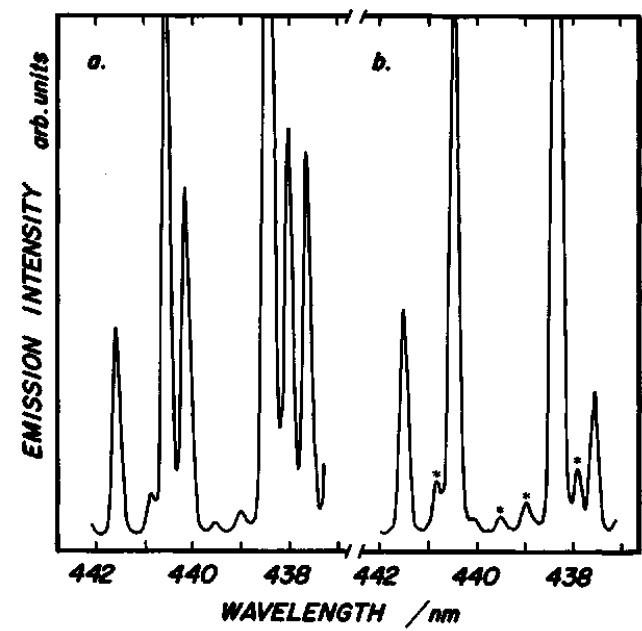

Fig. 2 Spectrum of Fe-0.54 at\% V binary alloy sample detected with (a) the $f_{1}$-modulation method and with (b) the $f_{2}$ modulation method (see text). The emission lines denoted by asterisks are derived from vanadium.

free spectra: the emission lines were detected at a frequency of $f_{1}(807 \mathrm{~Hz})$ and at $f_{2}(108 \mathrm{~Hz})$, respectively. As described above, the emission signals derived from sputtered atoms can only be detected as those tuned to the frequency of $f_{2}\left(f_{2}\right.$-modulation mode). On the other hand, the spectra patterns measured at a frequency of $f_{1}$ ( $f_{1}$-modulation mode) are almost the same as those produced with a conventional d.c. amplification method. ${ }^{8}$ Figure 2 shows spectrum scans of an alloy sample containing 0.56 at $\% \mathrm{~V}$ recorded in the $f_{1}$-modulation mode (a) and in the $f_{2}$-modulation mode (b) in the wavelength range between 437 and $442 \mathrm{~nm}$. In Fig. 2(b), the emission lines denoted by asterisks are attributed to vanadium line. No emission lines derived from Ar atoms and ions appear in the vicinity of the relatively weak lines, V I $439.00 \mathrm{~nm}$ and $439.59 \mathrm{~nm}$; as expected from Table 3 . In fact, Fig. 2 shows little change in the relative intensities of these lines, independent of the detection mode. However, it is clearly found that the intensity of the VI $437.92 \mathrm{~nm}$ line is strongly modified due to the Ar II $437.97 \mathrm{~nm}$ line when using the $f_{1}$-modulation mode. This implies that the most sensitive line of vanadium cannot be employed as the analytical line in the $f_{1}$-modulation method, whereas the emission line can be available for the analysis of vanadium in the $f_{2}$-modulation method.

An internal standarization method was employed in order to compensate for fluctuation in the discharge. In this study, the Fe I $441.51 \mathrm{~nm}$ line was chosen as the internal standard line (see Table 3). Accordingly, the emission intensities of the $\mathrm{VI}$ lines are expressed as the intensity ratios $(\mathrm{VI} / \mathrm{Fe} \mathrm{I})$, which can be converted to the atomic ratios $(\mathrm{V} / \mathrm{Fe})$ with the corresponding calibration factors.

Figure 3 illustrates the calibration graphs obtained for the analytical VI $437.92 \mathrm{~nm}$ (closed circles) and V I

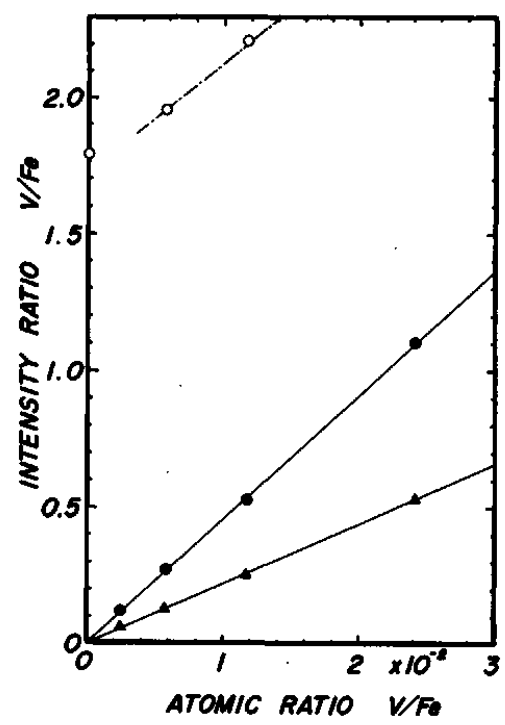

Fig. 3 Calibration curves of the intensity ratios; (O) V I 437.92/Fe I 441.51 and (A) V I 439.00/Fe I 441.51 measured under the $f_{2}$-modulation mode, and $(O)$ V I $437.92 / \mathrm{Fe} \mathrm{I}$ 441.51 under the $f_{1}$-modulation mode (see text).

$439.00 \mathrm{~nm}$ (triangles) lines obtained in the $f_{2}$-modulation mode. Linear relationships between the intensity ratios and the atomic ratios were obtained with correlation coefficients of more than 0.999 for all of the analytical lines listed in Table 2 . The intercepts on the axis of the intensity ratio were almost zero for all of the calibration curves. On the other hand, as can be seen from the plots of the intensity ratio of (V I 437.92/Fe I 441.51) shown in Fig. 3 (open circles), the high background level is caused by the Ar II $437.61 \mathrm{~nm}$ line. In general, the emission intensities of the Ar II lines are very sensitive to any change in the plasma conditions, especially those related to impurity gases in the plasma. ${ }^{13}$ It is thus rather difficult to determine the content of vanadium at lower concentrations.

\section{Effect of third alloyed elements}

Table 4 gives the analytical results concerning the concentrations of vanadium in these samples, together with the certified values. ${ }^{10}$ It is likely to be concluded that the influences of nickel, chromium, tungsten and molybdenum on the vanadium determinations is negligibly small for all of the vanadium lines. In the case of the $\mathrm{Fe}-\mathrm{Mn}(9.82 \%)-\mathrm{V}$ alloy, however, regardless of the vanadium line employed, the analytical values are found to be lower than the atomic ratio $(0.0259$, see Table 4$)$ computed from the certified composition. This effect is probably due to spectral interference of the MnI $441.49 \mathrm{~nm}$ line against the internal standard Fe I $441.51 \mathrm{~nm}$ line. Because the actual composition ranges of manganese in commercial tool steels are of the order of $0.1 \%$, the interference causes no serious problem. 
Table 4 Analytical results on vanadium determination in ternary standard samples

\begin{tabular}{|c|c|c|c|c|c|c|c|c|c|c|c|c|c|c|}
\hline \multirow{3}{*}{ Sample ${ }^{a}$} & & & \multicolumn{12}{|c|}{ Observed value } \\
\hline & \multicolumn{2}{|c|}{ Certified } & \multicolumn{3}{|c|}{ V I 440.8} & \multicolumn{3}{|c|}{ V I 439.5} & \multicolumn{3}{|c|}{ V I 438.9} & \multicolumn{3}{|c|}{ VI 437.9} \\
\hline & $\mathrm{V}$ at $\%$ & $\mathrm{~V} / \mathrm{Fe}$ & No. ${ }^{b}$ & $\mathrm{~V} / \mathrm{Fe}$ & $\operatorname{RSD}(\%)^{\mathrm{c}}$ & No. & $\mathrm{V} / \mathrm{Fe}$ & $\operatorname{RSD}(\%)$ & No. & $\mathrm{V} / \mathrm{Fe}$ & RSD $(\%)$ & No. & $\mathrm{V} / \mathrm{Fe}$ & $\operatorname{RSD}(\%)$ \\
\hline $\begin{array}{l}\text { FXS-431 } \\
\text { Fe-Ni-V } \\
(\mathrm{Ni} \mathrm{20.19 \% )}\end{array}$ & 2.31 & 0.0298 & $\begin{array}{l}4 \\
5 \\
5 \\
5\end{array}$ & $\begin{array}{l}0.029_{2} \\
0.028_{4} \\
0.029_{4} \\
0.029_{6}\end{array}$ & $\begin{array}{l}2.7 \\
3.4 \\
2.1 \\
3.0\end{array}$ & $\begin{array}{l}4 \\
5 \\
5 \\
5\end{array}$ & $\begin{array}{l}0.029_{1} \\
0.028_{7} \\
0.028_{9} \\
0.029_{4}\end{array}$ & $\begin{array}{l}3.2 \\
2.2 \\
2.0 \\
2.2\end{array}$ & $\begin{array}{l}4 \\
5 \\
5 \\
5\end{array}$ & $\begin{array}{l}0.029_{8} \\
0.028_{6} \\
0.029_{6} \\
0.029_{6}\end{array}$ & $\begin{array}{l}2.5 \\
2.8 \\
2.6 \\
1.3\end{array}$ & $\begin{array}{l}4 \\
5 \\
5 \\
5\end{array}$ & $\begin{array}{l}0.029_{6} \\
0.027_{8} \\
0.029_{6} \\
0.030_{6}\end{array}$ & $\begin{array}{l}1.2 \\
3.9 \\
2.4 \\
3.0\end{array}$ \\
\hline $\begin{array}{l}\text { FXS-439 } \\
\qquad \begin{array}{l}\text { Fe-Cr-V } \\
\text { (Cr 19.82\%) }\end{array}\end{array}$ & 1.52 & 0.0200 & $\begin{array}{l}5 \\
5 \\
4 \\
5\end{array}$ & $\begin{array}{l}0.020_{6} \\
0.020_{0} \\
0.019_{2} \\
0.019_{3}\end{array}$ & $\begin{array}{l}2.3 \\
3.0 \\
1.9 \\
1.5\end{array}$ & $\begin{array}{l}5 \\
5 \\
4 \\
5\end{array}$ & $\begin{array}{l}0.020_{6} \\
0.019_{7} \\
0.019_{8} \\
0.018_{7}\end{array}$ & $\begin{array}{l}4.1 \\
4.1 \\
8.6 \\
7.3\end{array}$ & $\begin{array}{l}5 \\
5 \\
4 \\
5\end{array}$ & $\begin{array}{l}0.020_{5} \\
0.018_{8} \\
0.020_{1} \\
0.018_{9}\end{array}$ & $\begin{array}{l}3.3 \\
4.5 \\
3.6 \\
3.3\end{array}$ & $\begin{array}{l}5 \\
5 \\
4 \\
5\end{array}$ & $\begin{array}{l}0.021_{8} \\
0.020_{7} \\
0.019_{7} \\
0.019_{4}\end{array}$ & $\begin{array}{l}2.1 \\
3.3 \\
2.0 \\
4.1\end{array}$ \\
\hline $\begin{array}{l}\text { FXS-466 } \\
\text { Fe-W-V } \\
\text { (W 5.06\%) }\end{array}$ & 2.27 & 0.0238 & $\begin{array}{l}6 \\
5 \\
4 \\
4\end{array}$ & $\begin{array}{l}0.024_{1} \\
0.023_{3} \\
0.023_{1} \\
0.023_{1}\end{array}$ & $\begin{array}{l}1.3 \\
2.7 \\
1.1 \\
3.2\end{array}$ & $\begin{array}{l}5 \\
5 \\
4 \\
4\end{array}$ & $\begin{array}{l}0.023_{0} \\
0.023_{9} \\
0.023_{4} \\
0.023_{0}\end{array}$ & $\begin{array}{l}4.0 \\
4.2 \\
2.4 \\
2.1\end{array}$ & $\begin{array}{l}5 \\
5 \\
4 \\
4\end{array}$ & $\begin{array}{l}0.023_{2} \\
0.023_{5} \\
0.023_{2} \\
0.022_{7}\end{array}$ & $\begin{array}{l}2.2 \\
4.4 \\
2.2 \\
3.2\end{array}$ & $\begin{array}{l}6 \\
5 \\
4 \\
4\end{array}$ & $\begin{array}{l}0.023_{9} \\
0.022_{8} \\
0.023_{2} \\
0.023_{5}\end{array}$ & $\begin{array}{l}2.3 \\
2.7 \\
1.4 \\
2.8\end{array}$ \\
\hline $\begin{array}{l}\text { FXS-446 } \\
\text { Fe-Mo-V } \\
\quad(\text { Mo } 3.03 \%)\end{array}$ & 2.21 & 0.0232 & $\begin{array}{l}5 \\
5 \\
4 \\
5\end{array}$ & $\begin{array}{l}0.022_{8} \\
0.022_{9} \\
0.022_{8} \\
0.021_{9}\end{array}$ & $\begin{array}{l}1.3 \\
3.6 \\
1.8 \\
3.0\end{array}$ & $\begin{array}{l}5 \\
5 \\
4 \\
5\end{array}$ & $\begin{array}{l}0.021_{9} \\
0.023_{2} \\
0.022_{9} \\
0.023_{4}\end{array}$ & $\begin{array}{l}1.9 \\
1.7 \\
2.6 \\
3.5\end{array}$ & $\begin{array}{l}5 \\
5 \\
4 \\
5\end{array}$ & $\begin{array}{l}0.021_{8} \\
0.023_{5} \\
0.023_{1} \\
0.022_{5}\end{array}$ & $\begin{array}{l}3.3 \\
6.4 \\
3.3 \\
4.3\end{array}$ & $\begin{array}{l}5 \\
5 \\
4 \\
5\end{array}$ & $\begin{array}{l}0.023_{7} \\
0.024_{1} \\
0.024_{2} \\
0.022_{8}\end{array}$ & $\begin{array}{l}2.4 \\
4.9 \\
2.5 \\
2.5\end{array}$ \\
\hline $\begin{array}{l}\text { FXS-422 } \\
\text { Fe-Mn-V } \\
\text { (Mn 9.82\%) }\end{array}$ & 2.24 & 0.0259 & $\begin{array}{l}5 \\
5 \\
5 \\
5\end{array}$ & $\begin{array}{l}0.023_{4} \\
0.023_{5} \\
0.023_{5} \\
0.023_{6}\end{array}$ & $\begin{array}{l}1.6 \\
2.1 \\
2.0 \\
3.2\end{array}$ & $\begin{array}{l}5 \\
5 \\
5 \\
5\end{array}$ & $\begin{array}{l}0.022_{8} \\
0.023_{1} \\
0.023_{1} \\
0.023_{1}\end{array}$ & $\begin{array}{l}7.4 \\
2.7 \\
2.1 \\
1.8\end{array}$ & $\begin{array}{l}5 \\
5 \\
4 \\
5\end{array}$ & $\begin{array}{l}0.023_{2} \\
0.023_{2} \\
0.023_{1} \\
0.023_{6}\end{array}$ & $\begin{array}{l}3.7 \\
2.7 \\
2.5 \\
4.4\end{array}$ & $\begin{array}{l}5 \\
5 \\
4 \\
5\end{array}$ & $\begin{array}{l}0.024_{7} \\
0.024_{3} \\
0.023_{1} \\
0.024_{7}\end{array}$ & $\begin{array}{l}2.1 \\
2.9 \\
1.0 \\
4.3\end{array}$ \\
\hline
\end{tabular}

a. Fe-V-X ternary standard samples ${ }^{10}$ for $\mathrm{X}$-ray fluorescence analysis. b. Number of measurements. c. Relative standard deviation.

Table 5 Analytical results on vanadium determination in commercial tool steels

\begin{tabular}{|c|c|c|c|c|c|c|c|c|c|c|c|c|c|c|}
\hline \multirow{3}{*}{ Sample } & & & \multicolumn{12}{|c|}{ Observed value } \\
\hline & \multicolumn{2}{|c|}{ Certified $^{a}$} & \multicolumn{3}{|c|}{ V I 440.8} & \multicolumn{3}{|c|}{ V I 439.5} & \multicolumn{3}{|c|}{ V I 438.9} & \multicolumn{3}{|c|}{ VI 437.9} \\
\hline & V at $\%$ & $\mathrm{~V} / \mathrm{Fe}$ & No. ${ }^{b}$ & $\mathrm{~V} / \mathrm{Fe}$ & $\operatorname{RSD}(\%)^{c}$ & No. & $\mathrm{V} / \mathrm{Fe}$ & $\operatorname{RSD}(\%)$ & No. & $\mathrm{V} / \mathrm{Fe}$ & $\operatorname{RSD}(\%)$ & No. & $\mathrm{V} / \mathrm{Fe}$ & $\operatorname{RSD}(\%)$ \\
\hline \multirow[t]{3}{*}{ SKH-9 } & 2.26 & 0.0272 & 5 & $0.027_{7}$ & 2.0 & 5 & $0.026_{6}$ & 2.8 & 5 & $0.027_{4}$ & 3.6 & 5 & $0.029_{8}$ & 4.1 \\
\hline & & & 5 & $0.027_{2}$ & 3.7 & 4 & $0.026_{1}$ & 3.8 & 4 & $0.026_{4}$ & 2.7 & 4 & $0.028_{4}$ & 0.2 \\
\hline & & & 5 & $0.027_{2}$ & 3.6 & 5 & $0.026_{1}$ & 0.5 & 5 & $0.027_{\text {I }}$ & 2.5 & 5 & $0.027_{3}$ & 3.1 \\
\hline \multirow[t]{3}{*}{ SKD-61 } & 1.00 & 0.0114 & 5 & $0.012_{4}$ & 2.7 & 5 & $0.011_{7}$ & 6.9 & 5 & $0.012_{1}$ & 3.5 & 5 & $0.013_{0}$ & 5.6 \\
\hline & & & 5 & $0.011_{3}$ & 2.9 & 5 & $0.011_{5}$ & 6.0 & 5 & $0.011_{4}$ & 3.4 & 5 & $0.011_{9}$ & 5.8 \\
\hline & & & 5 & $0.011_{1}$ & 2.4 & 5 & $0.010_{9}$ & 4.2 & 5 & $0.010_{7}$ & 4.1 & 5 & $0.010_{7}$ & 7.9 \\
\hline \multirow[t]{3}{*}{ SKD-12 } & 0.46 & 0.0053 & 5 & 0.0055 & 3.2 & 5 & 0.0049 & 9.3 & 5 & 0.0052 & 7.4 & 5 & 0.0056 & 7.4 \\
\hline & & & 5 & 0.0054 & 3.0 & 5 & 0.0056 & 9.7 & 5 & 0.0052 & 6.4 & 5 & 0.0050 & 7.8 \\
\hline & & & 5 & 0.0056 & 4.0 & 5 & 0.0053 & 9.6 & 5 & 0.0052 & 11.6 & 5 & 0.0053 & 6.2 \\
\hline \multirow[t]{3}{*}{ SKD-4 } & 0.34 & 0.0043 & 4 & 0.0044 & 2.3 & 4 & 0.0041 & 10.6 & 4 & 0.0042 & 12.2 & 4 & 0.0048 & 4.8 \\
\hline & & & 4 & 0.0047 & 2.8 & 4 & 0.0045 & 9.8 & 4 & 0.0043 & 13.6 & 4 & 0.0050 & 5.8 \\
\hline & & & 5 & 0.0045 & 6.4 & 5 & 0.0043 & 8.2 & 5 & 0.0044 & 7.4 & 5 & 0.0047 & 7.8 \\
\hline \multirow[t]{3}{*}{ SKS-42 } & 0.26 & 0.0028 & 5 & 0.0031 & 4.0 & 4 & 0.0029 & 5.9 & 4 & 0.0029 & 5.2 & 4 & 0.0033 & 13.1 \\
\hline & & & 5 & 0.0030 & 4.2 & 5 & 0.0029 & 11.9 & 5 & 0.0028 & 2.5 & 5 & 0.0027 & 6.3 \\
\hline & & & 5 & 0.0029 & 4.7 & 5 & 0.0029 & 8.1 & 5 & 0.0028 & 5.1 & 5 & 0.0032 & 3.9 \\
\hline \multirow[t]{3}{*}{ SKS-11 } & 0.19 & 0.0021 & 4 & 0.0023 & 4.0 & 4 & 0.0029 & 9.9 & 4 & 0.0020 & 11.3 & 4 & 0.0024 & 5.0 \\
\hline & & & 5 & 0.0025 & 5.8 & 5 & 0.0026 & 10.6 & 5 & 0.0026 & 6.6 & 5 & 0.0027 & 5.2 \\
\hline & & & 5 & 0.0023 & 7.8 & 5 & 0.0025 & 12.6 & 5 & 0.0024 & 4.8 & 5 & 0.0024 & 7.2 \\
\hline
\end{tabular}

a. The certified values are cited from the report ${ }^{11}$ of the committee on X-ray fluorescence analysis. b. Number of measurements. c. Relative standard deviation. 
Determination of vanadium in tool steels

Based on the calibration factors obtained with the Fe-V binary alloys, analytical results concerning the concentration of vanadium in some commercial tool steels were determined under the $f_{2}$-modulation mode. As shown in Table 5, triplicate individual determinations were carried out for each test sample. These reproducibilities in each data are satisfactory and the analytical values are similarly independent of the vanadium line employed. Furthermore, our values are in good agreement with the certified values ${ }^{11}$, although the results for SKS-11 seem to be slightly high compared to the certified concentration.

The $f_{2}$-modulation method enables the most intensive V I $437.92 \mathrm{~nm}$ line to be used as the analytical line. The proposed method may also overcome the problem associated with intensity fluctuations of the overlapping argon lines, which may degrade the precision of data when the $f_{1}$-modulation and the conventional detection method is used.

\section{References}

1. C. J. Belle and J. D. Johnson, Appl. Spectrosc., 27, 118 (1973).
2. M. E. Waitlervertch and J. D. Hurwitz, Appl. Spectrosc., 30, 510 (1976).

3. R. Berneron and J. C. Charbonnier, Surf. Interface Anal., 3, 134 (1981).

4. W. B. Teo and K.Hirokawa, Surf. Interface Anal., 11, 421 (1988).

5. K. Tsuji and K. Hirokawa, Surf. Interface Anal., 15, 223 (1990).

6. R. Mavrodineau, J. Res. Natl. Bur. Stand., 89, 143 (1984).

7. K. Wagatsuma and K. Hirokawa, Anal. Chem., 57, 2901 (1985).

8. K. Wagatsuma and K. Hirokawa, Spectrochim. Acta, 42B, 523 (1987).

9. K. Wagatsuma and K. Hirokawa, Anal. Chem., 61, 2137 (1989).

10. "X-ray fluorescence analysis of steel materials", The Iron and Steel Institute of Japan, Tokyo, 1973.

11. FX-112, "Summary on chemical analyses of steel samples for the standards in X-ray fluorescence spectrometry", The Report of Committee on X-ray Fluorescence Analysis, The Iron and Steel Institute of Japan, Tokyo, 1966.

12. C. E. Moore, “Atomic Energy Levels", Natl. Bur. Stands. (U. S.) Circular 467, 1949.

13. K. Wagatsuma and K. Hirokawa, Anal. Chem., 61, 326 (1989).

(Received October 12, 1990) (Accepted January 14, 1991) 